\title{
Webcam, sexo, espetáculo e vigilância: reflexões sobre a campanha sweetie a partir da cultura visual
}

\section{PABLO PETIT PASSOS SÉRVIO \\ RAIMUNDO MARTINS}

\section{Resumo}

Ao desenvolver reflexões sobre experiências visuais contemporâneas relevantes para a Cultura Visual, este artigo utiliza a campanha Sweetie da ONG holandesa Terre des Hommes, que denuncia o fenômeno do turismo sexual por webcam. Discutimos a pornografia via webcam, sua relação com o voyeurismo, narcisismo e exibicionismo analisando: o modo como espetáculo se confunde com vigilância e vigilância se confunde com espetáculo na estrutura social global possibilitada na web; relações de poder, de classe, gênero e etnia que marcam o turismo sexual via webcam denunciado por Terre des Hommes; expectativas de veracidade que nutrimos em relação às imagens de webcam. $\mathrm{E}$, por fim, discutimos interações com imagens de corpos que menosprezam a ética em favor da estética ao explorar o desejo de controle e a autoestimulação subjetiva de prazeres.

Palavras-chave:

Cultura visual, vigilância, espetáculo, webcams 


\title{
Webcam, sex, spectacle and surveillance: visual culture reflections about the Sweetie campaign
}

\author{
PABLO PETIT PASSOS SÉRVIO \\ RAIMUNDO MARTINS
}

\begin{abstract}
In developing reflections about contemporary visual experiences relevant to Visual Culture, this article uses Sweetie, the campaign of the Dutch NGO Terre des Hommes that denounces the phenomenon of sex tourism by webcam. We discuss webcam pornography, its relationship with voyeurism, narcissism and exhibitionism analyzing how spectacle is confused with surveillance and surveillance is confused with spectacle in the global social structure made possible on the web. Relations of power, class, gender and ethnicity mark the webcam sex tourism denounced by Terre des Hommes confronting the expectations of veracity we nourish for webcam images. Finally, we discuss interactions with body images that disparage ethics in favor of aesthetics by exploring the desire for control and subjective self-stimulation of pleasures.
\end{abstract}

Keywords: 


\section{Webcam, sexo, espectáculo y vigilancia: reflexiones a partir de la cultura visual sobre la campaña Sweetie}

\section{PABLO PETIT PASSOS SÉRVIO \\ RAIMUNDO MARTINS}

\section{Resumen}

Para desarrollar reflexiones sobre experiencias visuales contemporáneas relevantes para la Cultura Visual, este artículo utiliza la campaña Sweetie de la ONG holandesa Terre des Hommes que denuncia el fenómeno del turismo sexual por webcam. Discutimos la pornografía por webcam, su relación con el voyeurismo, narcisismo y exhibicionismo analizando como el espectáculo se confunde con vigilancia y vigilancia se confunde con espectáculo en la estructura social global posibilitada en la web. Relaciones de poder, de clase, género y etnia que marcan el turismo sexual por webcam denunciado por Terre des Hommes confrontan las expectativas de veracidad que nutrimos en relación con imágenes de webcam. Por fin, discutimos interacciones con imágenes de cuerpos que menosprecian ética a favor de la estética a explorar el deseo de control y la autoestimulación subjetiva de placeres.

Palabras clave:

Visual culture, surveillance, spectacle, webcams 
Figura 1: Avatar Sweetie.

Fonte: <https://www. terredeshommes.nl/sites/tdh/ files/uploads/Sweetie-2_2.jpg>. Acesso em: 10 ago. 2017.
Sweetie é uma campanha criada pela agência de publicidade alemã Lemz para promover a ONG holandesa Terre des Hommes e sua missão: atuar na conscientização da sociedade sobre as consequências da pornografia infantil, em especial aquela possibilitada pela rede mundial de computadores. A ação desenvolvida pela agência começou com a criação do avatar de uma garota filipina. A escolha desse perfil se deu em função de indicar um público bastante afetado pelo mercado do turismo sexual. Esse modelo digital em $3 \mathrm{D}$ foi, em seguida, programado de forma a interagir através de 19 sites que permitem a comunicação via webcam e que são utilizados por consumidores daquilo que a ONG caracteriza como turismo sexual por webcam. Por meio de Sweetie, nome utilizado pelo modelo 3D nos sites, a agência vigiou e identificou criminosos, predadores sexuais ${ }^{1}$ de 71 países.

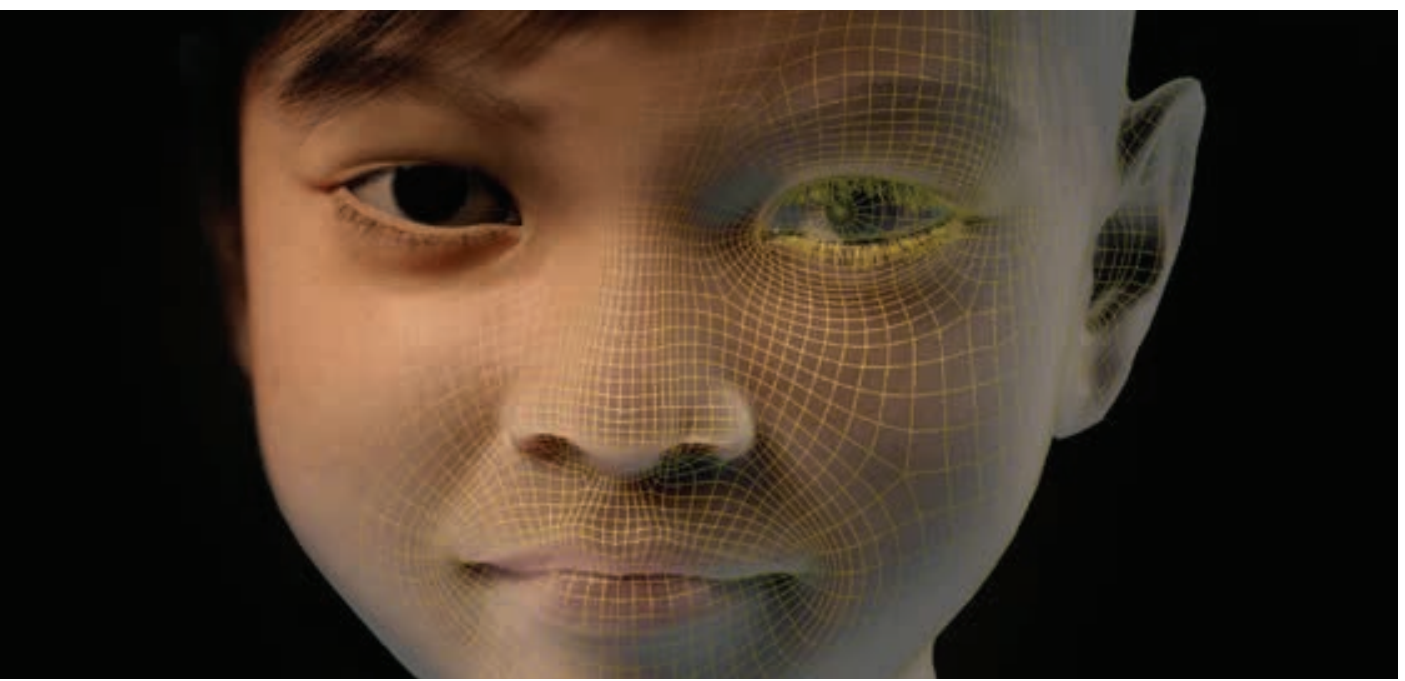


Acreditamos que Sweetie aponta de modo direto e indireto para uma série de fenômenos associados a experiências visuais contemporâneas. Em decorrência, decidimos utilizar esta campanha como elemento deflagrador de reflexões relevantes para os Estudos Visuais, ou seja, o campo de estudos em Cultura Visual. O texto, deliberadamente, não tem como foco apenas os crimes ressaltados em Sweetie. Além de possibilitar uma discussão do fenômeno da pornografia por webcam, este exemplo sinaliza novas manifestações da sexualidade nas quais imagens ganham centralidade estimulando prazeres escópicos voyeuristas, exibicionistas e narcisistas. Sweetie evidencia o modo como espetáculo se confunde com vigilância e vigilância se confunde com espetáculo na estrutura social global possibilitada na web. Assim, aproveitamos para discutir duas teorias caras ao campo dos estudos visuais, a teoria da sociedade do espetáculo (DEBORD, 1997) e da sociedade da vigilância (FOUCAULT, 1987). Pensando especificamente nos crimes denunciados por Sweetie, podemos partir desta campanha para refletir sobre uma das principais preocupações da Cultura Visual: os modos como relações de poder invadem e conformam experiências visuais. Pretendemos demonstrar que classe, gênero e etnia são fundamentais para compreender o turismo sexual por webcam. Queremos, ainda, discutir sobre o quanto a estratégia da campanha Sweetie utiliza-se de expectativas nutridas em relação às imagens. A partir de Sweetie almejamos refletir sobre as relações que estabelecemos com imagens, relações que vão além da simples crença quanto à veracidade do que elas representam, da sua objetividade, e que enfatizam interações orientadas pelo desejo de controle e pela autoestimulação subjetiva de prazeres.

\section{Sexo, webcams, espetáculo e vigilância}

A Cultura Visual investiga como se interligam cultura e experiências visuais (MITCHELL, 2002), ou seja, o modo como nossa dimensão cultural influencia como vivenciamos nossas experiências visuais e como promove formas de relações sociais que organizam nossas experiências visuais; em contrapartida, temos também o papel das experiências visuais, seu espaço na organização de estruturas de sociabilidade que efetivam práticas de produção de significado e modos de subjetivação. Sendo assim, antes de aprofundar-nos em questões específicas da campanha Sweetie, acreditamos que do ponto de vista do campo da Cultura Visual é importante 
buscar compreender aspectos das estruturas sociais e as relações de poder que conformam experiências visuais vivenciadas ao navegar em sites de webcam nos quais se pode visualizar e distribuir cenas de performances sexuais.

Duas teorias fundamentais para a Cultura Visual caracterizam a modernidade como estando amplamente marcada por estruturas que organizam a sociabilidade por meio do olhar: a teoria da sociedade de vigilância de Michael Foucault (1987) e da sociedade do espetáculo de Guy Debord (1997). Sendo a experiência de sexualidade vivenciada por meio de webcams uma experiência amplamente visual, podem as teorias do espetáculo e da vigilância contribuírem com insights que nos ajudem a pensá-las? Acreditamos que sim, desde que algumas ressalvas sejam feitas. As duas teorias se complementam? Como usá-las para pensar um ambiente social e tecnológico distinto daquele sobre o qual se debruçaram Foucault ou Debord?

Um primeiro problema é a perspectiva deixada por Foucault (1987) de que as duas propostas não se coadunam. Enquanto Debord (1997) alertava sobre o fato de o capitalismo nos controlar regulando o "que" e "como" vemos, nos colocando na posição de espectadores isolados, Foucault (1987), em oposição, argumenta que não vivemos em uma sociedade do espetáculo, mas em uma sociedade na qual corpos são domesticados a partir de técnicas de vigilância. Ou seja, mais importaria percebermo-nos na posição de sujeitos vigiados.

Jonathan Crary $(2012$; 1989) é um dos autores que se dedicou a revisar esta suposta oposição ressaltando que uma estratégia de poder não exclui a outra. Para Crary, ao negar o espetáculo, Foucault "negligencia os novos modos pelos quais a própria visão se converte em um tipo de disciplina ou forma de trabalho" (2012, p. 26). O espetáculo, de acordo com Crary (1989, p. 105), "é um conjunto de técnicas para o gerenciamento de corpos, o gerenciamento da atenção". Concordando com a análise de Debord (1997, p. 18) sobre a atual "tendência a fazer ver um mundo que já não se pode tocar diretamente" e, em sintonia com Crary (2012), acreditamos que é importante destacar o modo como somos treinados para um consumo que é pautado na "ruptura entre o que é palpável e o que é visível” (CRARY, 2012, p. 28), um consumo espetacular.

Corroborando com a análise de Crary (2012; 1989), Bennett (1988) identifica que em paralelo a técnicas de confinamento e vigilância descritas por Foucault, uma série de instituições - museus de história e de ciência natural, dioramas e pano- 
ramas, exibições internacionais e nacionais, lojas de departamento - e disciplinas, como história, biologia, história da arte e antropologia, se dedicam desde o século XIX a responder às demandas modernas de ver e fazer ver. Bennett argumenta que não se deve pensar o espetáculo como o inverso da vigilância porque o espetáculo também tem como função regular a multidão ao determinar quem pode (deve) ver o "que" e "como ver"2. Bennett (1988) sublinha que pensar o papel de instituições, como o museu no século XIX, exige perceber essas instituições também como lugar de exibição dos próprios visitantes. Destaca que a própria sociedade foi organizada como espetáculo "através do desenvolvimento de tecnologias da visão que tornaram a multidão acessível à sua própria inspeção” (Bennett, 1988, p. 98). Assim, fica evidente que a multidão, ou seja, os indivíduos, não estão lá apenas para olhar, mas, para serem vistos e, desse modo, todos se tornam espetáculo, assim como também assumem o lugar de vigilantes uns dos outros. Nesse sentido, Machado (2001, p. 226) ressalta que:

Nossa sociedade - retomando novamente Foucault - é menos a dos espetáculos do que a da vigilância. Mas a sua sabedoria está em transformar o próprio espetáculo em observatório de vigilância. [...] Mas a recíproca também é verdadeira: em nossa sociedade marcada pelo destino do Panóptico, a própria vigilância resulta também em espetáculo.

Não há dúvida de que nos dias de hoje esta análise cresce em importância devido ao desenvolvimento de tecnologias que permitem a ampliação do ver e do ser visto, possibilitando que sejamos ao mesmo tempo produtores do espetáculo e consumidores da vigilância. A web é fundamental para esta transformação, esta que é também o nó conector de inúmeras webcams. Mas a web é também um ambiente novo que exige revisões das teorias do espetáculo e da vigilância assim como as pensaram seus autores.

A web não é apenas um lugar onde temos acesso a conteúdos, é também uma máquina para vigiar nossas ações (KEEN, 2012). Nela é cada vez mais difícil ver sem ser visto. Imagens, textos, sons que vemos e criamos, nosso percurso e ação são objeto de análise por empresas, partidos e governos. Em um círculo contínuo ela possibilita, por exemplo, a interpretação desses dados por empresas como o Facebook que podem decidir que espetáculos retornar aos seus 
usuários. Segundo Bruno (2004), é preciso ressaltar que na rede há uma nova concepção de vigilância. Vigiar é cada vez menos confinar e regular, como no início da modernidade, e cada vez mais interceptar e interpretar. Aqui, além de todos vigiarem todos, não se exigem o confinamento e a redução das possibilidades de ação. Pelo contrário, a mobilidade dos indivíduos colabora com o enriquecimento dos bancos de dados, informações que podem ser acessadas não somente pela rede de amigos e conhecidos, mas, também, acessadas e interpretadas pelo Facebook e muitas outras empresas e instituições interessadas em tirar proveito financeiro desses dados. Isso ocorre também por um motivo distinto da vigilância panóptica tradicional, mais do que o interesse em "ver" o indivíduo, destaca-se agora a busca dessas empresas por utilizar a análise desses dados para "prever" tendências futuras no comportamento de populações.

As obras A more perfect union (2011), de R. Luke DuBois, e

Listening Post (2003), de Ben Rubin e Mark Hansen, exemplificam avaliações artísticas desse contexto de vigilância na web em que o processamento e a visualização de dados se tornam centrais. A primeira obra faz isso criando mapas a partir de informações de sites de relacionamento e a segunda, monitorando chats públicos e exibindo certas palavras simultaneamente a sua postagem.

Por outro lado, na rede, a vigilância se torna espetáculo primeiro por ampliar o acesso às cenas de "vigilância". Ao contrário da lógica da arquitetura panóptica em que poucos viam muitos e esses muitos não podiam ver-se, com a rede ocorre o contrário, a central de vigilância também está acessível, ou, pelo menos, muito mais acessível, ampliando as possibilidades do que se podia ver nas sociedades analisadas por Foucault (1987). Por outro lado, também podemos dizer que a vigilância se torna espetacularizada na medida em que se aproxima da lógica comercial das companhias de televisão, assim como analisou Debord (1997). Agora não apenas aquele pequeno número de corporações, mas nós mesmos, usuários da rede, criamos o que Sibilia (2008) descreve como o "show do eu”, uma vez que passamos também a exibir uma intimidade editada como espetáculo. Assim, a vigilância torna-se espetacularizada também na medida em que se espia não somente a vida pública nas escolas, hospitais e presídios. Cinema, tevê e rádio, os meios de comunicação paradigmáticos da sociedade do espetáculo analisada por Debord (1997), já exploravam a exibição da intimidade de figuras públicas, celebridades. 
Todavia, agora, tal situação de exposição da intimidade passa a ser vivenciada por muitos mais.

A obra Excellences $\mathcal{E}$ Perfections (2014), de Amalia Ulman, demonstra padrões visuais dessa intimidade tornada espetáculo. A artista criou uma "persona" que fez uma performance na rede social Instagram apropriando-se de estereótipos das fotografias, legendas e hashtags de celebridades da web. Na sua narrativa, ela mudou-se para viver em uma cidade grande, terminou com o namorado, usou drogas, se machucou, se recuperou e conseguiu um novo namorado. Quando revelou que tudo se tratava de uma performance, após cerca de seis meses, tinha mais de 88 mil seguidores.

Como afirma Bruno (2004, p. 119), "os dispositivos de visibilidade atuais oferecem o olhar do outro e uma cena pública numa realidade social onde o indivíduo só existe se ele é capaz de fazer saber que ele existe". Neste sentido, a ampliação da visibilidade torna-se até mesmo "condição almejada de existência e de reconhecimento" (BRUNO, 2004, p. 119). Assim, há disputa por atenção. Bruno (2004) identifica ainda nesse processo o anseio por auxílio na atribuição de sentido para nossa identidade e existência. Ou seja, esse fenômeno envolve mais do que se fazer ver para o "outro", aqui importa, também, ver a si e construir uma autoimagem. Trata-se de uma nova concepção de espetáculo na qual à maioria não cabe mais simplesmente a posição de espectadores, como identificara Debord (1997).

Esta discussão sobre o modo como na sociedade contemporânea o espetáculo ganha aspectos de vigilância e como a vigilância toma forma de espetáculo pode nos levar a refletir sobre as consequências dessa sociedade mediada por imagens e sobre como vivenciamos a sexualidade. Segundo Machado (2001, p. 227), em alguns motéis, alguns casais deixam-se filmar para que sua imagem seja exibida para outros casais, "a eventualidade de estar sendo vigiados dá um sabor de emoção à aventura”. Mais do que isso, descreve que "há casais que já não conseguem sentir atração sexual se não puderem contemplar-se, ao mesmo tempo, numa tela de TV" (MACHADO, 2001, p. 227). Machado (2001) destaca, de um lado, a excitação sexual provocada pela visão de si na forma de imagem, e de outro, a excitação em espiar imagens de outros e exibir-se para outros, ou seja, deixar-se vigiar. Estes exemplos descrevem como viver em um mundo de espetáculo e vigilância amplamente mediado por imagens pode produzir efeitos no âmbito da sexualidade. Essa interação complexa entre o prazer voyeurístico de tudo poder ver e vigiar, o prazer 
Figura 2 - Captura de tela do site Cam4 (imagem desfocada para não identificar usuários). Fonte: Arquivo pessoal, 2017. exibicionista de fazer-se espetáculo para os outros e o prazer narcisista de fazer-se espetáculo para si mesmo está amplamente disseminada na prática de sites de sexo por webcam.

Sites agregadores de webcam devotados a performances pornográficas, com o Cam4 (Figura 2), podem ser analisados a partir desta perspectiva. Neles, usuários do mundo inteiro exibem sua intimidade na forma de espetáculo, disputando atenção e tentando capitalizá-la. Nesses sites os performers estão constantemente sendo levados a refletir sobre a própria identidade frente à enxurrada de comentários emitidos por espectadores (LOPES, 2013). O site também coleta dados sobre as movimentações feitas pelos seus usuários. Um dos usos desse banco de dados é a promoção de anúncios publicitários personalizados, mas outros usos podem ser concebidos e utilizados, como o caso da campanha Sweetie demonstra. Os rastros virtuais podem ser utilizados para identificar usuários.

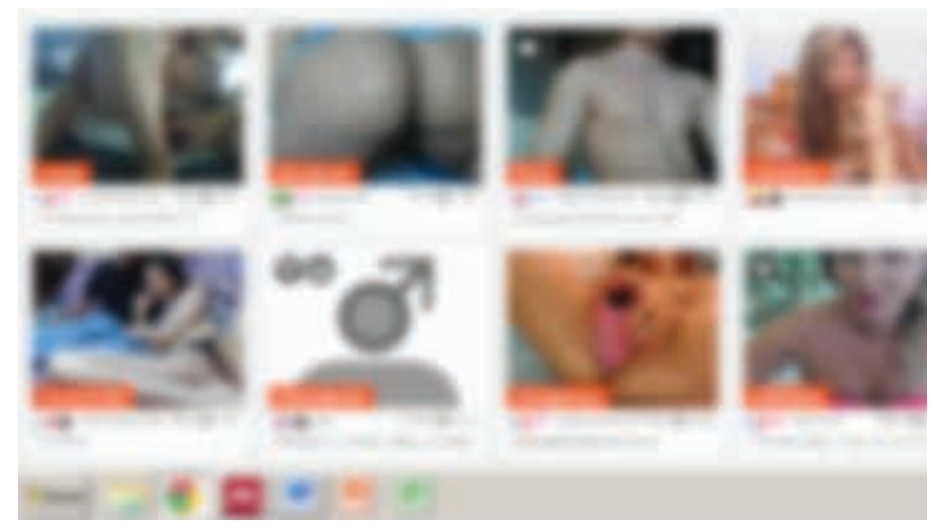

Ao fazer referência a sites de pornografia nos quais é possível visualizar e distribuir cenas de sexo por webcam, Sweetie nos leva a pensar em eventos visuais complexos. Nesse ambiente nem sempre é possível separar aqueles que veem daqueles que se exibem porque essas posições podem ser cambiantes ou até mesmo ocupadas ao mesmo tempo por todos os usuários. Ao contrário do $\mathrm{Cam}_{4}$, em que vários usuários veem as cenas da webcam de um performer sem se exibirem, outros sites de chat exigem que as duas webcams das pessoas que se conectam estejam ligadas. Neste caso, para pensar as relações de poder entre sujeitos convém considerar as trocas de olhares. Nestes sites as estratégias de poder não se resumem a assumir a posição de quem vê, vigia, controla ou 
objetifica, porque tais estratégias se efetivam também a partir do controle de "quem pode ver", "como deve ver", o "que" e quando se pode vir a ver.

Feitas essas ressalvas para contextualizar as lógicas que marcam o apelo de sites de webcams, podemos, agora, nos aprofundar na discussão sobre Sweetie. A campanha nos leva a refletir sobre um grupo específico de pessoas, crianças, mas especificamente meninas das Filipinas, que se exibem e comercializam sua imagem para grupos específicos de indivíduos consumidores, homens maiores de idade, principalmente europeus.

\section{Gênero, etnia e classe}

27,9\% da população das Filipinas está abaixo da linha de pobreza. Estima-se que entre 60 mil e 100 mil crianças filipinas sejam exploradas na prostituição e cerca de 10 mil estejam envolvidas nesse mercado criminoso do turismo sexual por webcam que vende cada minuto de vídeo pornográfico por algo entre 55 e 99 centavos de dólares americanos (WEBCAM CHILD SEX TOURISM..., 2013).

Sweetie denuncia o crescente impacto do turismo sexual por webcam sobre crianças de países pobres, como as Filipinas, consequência de um mercado aberto pela existência da tecnologia do chat por webcam, mas, também, pelo desejo de ver e de se exibir de homens muitas vezes de países distantes e ricos - países nos quais a pedofilia é crime e as crianças têm maior proteção social. As necessidades econômicas dessas crianças e suas famílias são fundamentais para este mercado criminoso, pois trata-se de uma condição econômica que as leva, muitas vezes, a depender desse único capital, o "capital erótico", para sua sobrevivência. Maycon Lopes (2013, p. 11), tomando como referência Catherine Hakim (2010), explica que em uma cultura altamente sexualizada é preciso considerar o capital erótico "como habilidade e potencialidade em seduzir e satisfazer sexualmente o outro". No caso denunciado por Sweetie, este outro é principalmente homem e ocidental.

Para a Cultura Visual é fundamental refletir sobre as relações de poder que marcam as experiências visuais, especialmente em sua vertente educacional. Temos a expectativa de participar dos jogos da cultura de modo a promover mudanças sociais, ou seja, considerar "uma educação mais centrada na busca de soluções para os problemas que afligem os nossos tempos, do que para uma contemplação romântica das quali- 
dades estéticas das imagens" (CHARRÉU, 2012, p. 52). Belidson Dias (2008, p. 39), ao debater sobre visualidade, afirma que a Educação da Cultura Visual promove "uma consciência crítica que conduz a ações assentadas para resistir processos de superioridades, hegemonias e dominação nas nossas vidas diárias". Nesse sentido, todas as variáveis que se envolvem nas desigualdades de poder tornam-se fundamentais para entendermos os eventos visuais. No caso de Sweetie, além das bases tecnológicas e das desigualdades de classe, gênero e etnia ganham importância.

O conceito de evento visual é fundamental para a Cultura Visual. Como propõem Illeris e Arvedsen (2012), pensamos nos eventos visuais por meio das seguintes questões: quem (ou o que) está na posição de sujeito que vê? De que forma ou com que interesse vê? Quem pode ver? Quem pode ver desta forma? O que ou quem pode (ou não) ou deve (ou não) ser visto? O que ou quem está na posição de objeto do olhar? Este objeto do olhar ocupa a posição da imagem de algo, representa algo? Em que contexto este evento se dá?

Tais questões estão em sintonia com a posição de Pollock (2011) ao afirmar que historicamente as mulheres não foram livres para ver, como foram os homens. Em primeiro lugar, porque as mulheres não são livres para transitar como observadoras pelos mesmos espaços que os homens. Em consequência, elas são consideradas mais como objetos da visão de homens do que como sujeitos que veem. Com identidade marcada como objeto da visão de homens, a presença das mulheres em espaços considerados inadequados pode, inclusive, converter/alterar o significado de sua feminilidade. Pollock (2011) afirma que as mulheres não são livres para ver como os homens no sentido de que o homem pode assumir a posição de pessoa erótica, evidenciar seu olhar desejoso e os prazeres escopofílicos. Ainda hoje, em vários contextos, as mulheres, embora mudanças estejam em marcha crescente, não têm o mesmo direito dos homens de assumir a posição de sujeito que vê eroticamente.

A obra Susanna e os velhos, de Artemisia Gentileschi, é conhecida pela crítica a esse olhar objetificador por dar à expressão de Susanna um misto de asco e pavor nunca antes narrado por artistas que já haviam se dedicado a representar essa passagem da bíblia. Esse olhar se perpetua em várias instâncias. Laura Mulvey (2011) analisa especificamente a forma como o olhar é direcionado no cinema de ficção narrativa. De acordo com Mulvey (2011, p. 121) um dos principais 
prazeres do cinema é o escopofílico, prazer de "objetificação de outrem, submetendo-o a uma contemplação controladora e curiosa (...)", uma vontade "de usar outra pessoa como objeto de estimulação sexual através da visão" (MULVEY, 2011, p. 123). Esse prazer é vivenciado no cinema tanto através do olhar dos próprios espectadores quanto através do olhar do herói da narrativa, em quem os espectadores tendem a fazer uma projeção narcísica de suas identidades possibilitando que vejam através dos olhos do herói. Mulvey (2011, p. 124-125) discute a distinção de papéis entre os gêneros ao explicitar que:

Num mundo estruturado por assimetrias sexuais, o prazer de olhar polarizou-se entre activo/homem e passivo/mulher. O determinante olhar masculino projecta a sua fantasia na figura feminina, que é moldada em conformidade. No seu papel tradicionalmente exibicionista, as mulheres são simultaneamente olhadas e expostas, com a sua aparência codificada para provocar um forte impacto visual e erótico, de tal maneira que possam ser conotadas as qualidades de serem olhadas. A mulher exibida como objeto sexual é o leitmotif do espetáculo erótico: das pin-ups ao strip-tease, de Ziegfeld a Busby Berkeley, ela prende o olhar, representa para o desejo masculino e é dele significado.

Tanto o olhar direto do espectador sobre a forma da mulher exibida quanto o olhar projetado pela identificação com o herói buscam "ganhar controle e posse da mulher na diegese" (MULVEY, 2011, p. 127), às vezes por meios sádicos, outras vezes tornando-a um objeto de fetiche. Embora a análise de Mulvey (2011) apele a aspectos da teoria freudiana questionados por suas suposições ontológicas, como as conjecturas sobre o trauma da castração, podemos aproveitá-la do ponto de vista de uma psicanálise pós-estruturalista, como defendem Kincheloe e McLaren (2006), ao argumentar que tal psique nada tem de natural porque estrutura-se historicamente, neste caso, a partir do patriarcado e do machismo.

Berger (1999) alertava sobre a insistência de forças na sociedade que intentam construir categorias de gênero e demarcar as posições que os gêneros masculino e feminino devem ocupar nos eventos visuais. Ao denunciar o desejo de homens de controlar a imagem de meninas, Sweetie, de maneira análoga, põe em evidência a permanência da fórmula consagrada por Berger (1999, p. 51): "os homens agem, as mulheres aparecem". Sim, aqui homens consomem, meninas vendem sua imagem. 
Resta incerto o quanto esses homens engajam-se nesse evento visual criminoso também se exibindo. Para compreender essa prática e as imagens proporcionadas por esses homens, é importante também avaliarmos os efeitos subjetivos que tais imagens provocam sobre a psique das crianças.

Seja qual for a razão, é evidente que Sweetie aponta para um fenômeno generificado. Segundo a ONG Terre des Hommes, dos mil predadores identificados pela campanha, apenas um era mulher. No caso da pornografia, vale ressaltar o quanto essa indústria ainda permanece comprometida com representações sexistas e machistas, retratando mulheres no lugar de objetos passivos cuja existência se justifica para a gratificação masculina, para o prazer de homens descritos como detentores de um poder natural sobre as mulheres.

Considerando que cada vez mais homens e mulheres, de pouca idade, têm na pornografia referência e experiência em que descobrem e constroem sua sexualidade, analisar e questionar essas imagens torna-se fundamental para a cultura visual. Como explica Fernando Hernandez (2007, p. 37), a Cultura Visual busca "se aproximar destes 'lugares' culturais, onde meninos e meninas, sobretudo os jovens, encontram hoje muitas de suas referências para construir suas experiências de subjetividades". É urgente investigar o lugar da pornografia na formação das novas gerações.

Para além dos aspectos de gênero, outra marcação identitária, a étnica, também tem sua influência no fenômeno denunciado por Sweetie. Jagodzinsky (2005, p. 668) lembra que o turismo sexual na Ásia está associado ao "desejo masculino de rapazes brancos por encontrar a diferença sexual não-branca como uma forma de perder a virgindade e entrar no mundo da 'experiência'. Baseando-se em bell hooks, o autor lembra o estereótipo de indivíduos não brancos como "mais exóticos e experientes sexualmente" (Jagodzinsky, 2005, p. 668). Citando as críticas de Griselda Pollock a Paul Gauguin, pintor europeu que já velho casou-se com uma menina taitiana de 13 anos, Teha'amana, Jagodzinsky (2005) ressalta que a história da arte também é cúmplice da sexualização do "outro".

Segundo a ONG holandesa Terre des Hommes, diariamente cerca de 750 mil homens buscam por sexo com crianças por webcam na internet. Durante as 10 semanas em que os pesquisadores da ONG utilizaram Sweetie, 20.172 homens requisitaram performances sexuais diante de oferta de pagamento, principalmente homens ocidentais (WEBCAM CHILD SEX TOURISM..., 2013). 


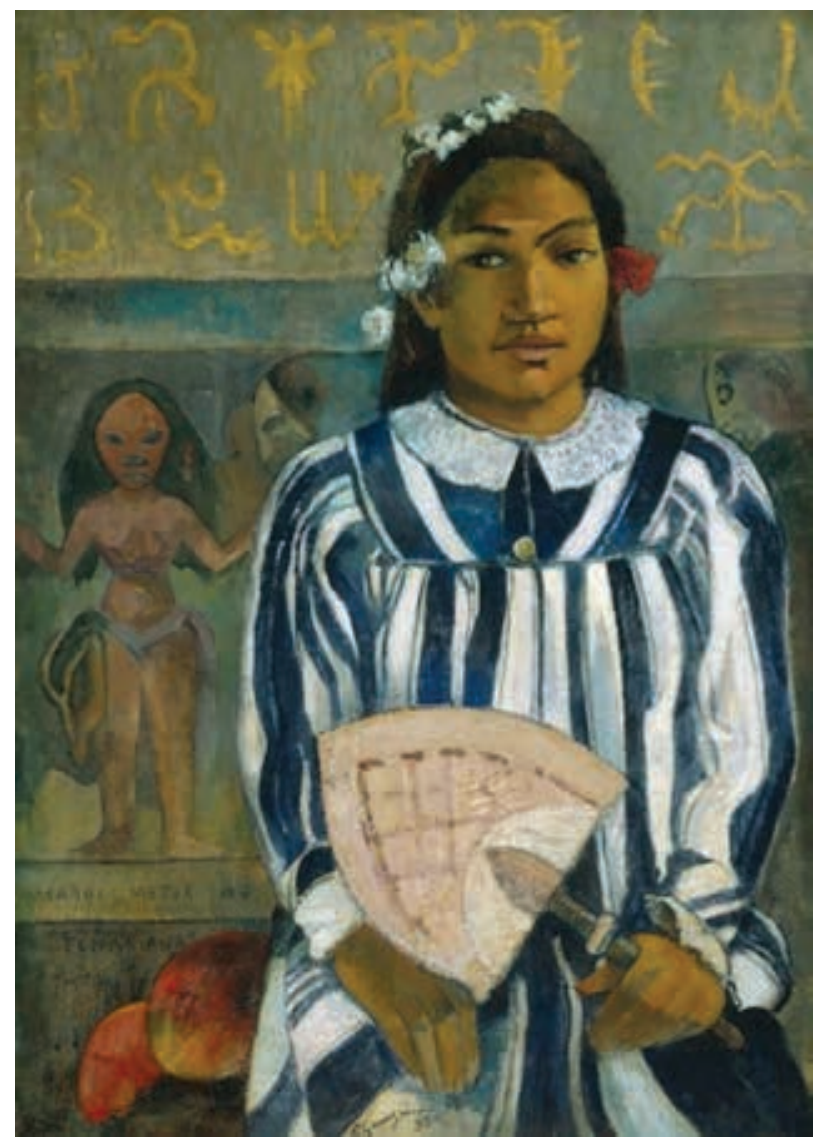

\section{Benesses da vigilância... e seus riscos}

Em sua obra Strip (200o), Jemina Stehli denuncia que no campo artístico, ainda dominado por homens, é mais fácil encontrar representações de mulheres, em geral nuas, do que encontrar artistas mulheres. Nessa obra a artista tira a roupa em frente a críticos de arte que, utilizando um dispositivo, têm o poder de decidir o momento em que a fotografia será tirada. A subversão de Stehli consiste em exibir esse voyeurismo tornando-o explícito. Em The Park (1971-73), o fotógrafo japonês Kohei Yoshiyuki investiga o comportamento voyeur de jovens japoneses que vão a parques para ver casais fazendo sexo. Além de se colocar na condição de voyeur, um dos dilemas clássicos do fotógrafo, o conjunto de fotografias de Yoshiyuki intriga ao nos fazer ver o voyeur. Fazer ver
Figura 3: Os ancestrais de Teha'Amana (1893) de Paul Gauguin.

Fonte: Disponível em: <https:// commons.wikimedia.org/wiki/ File:Paul_Gauguin_-_The_Ancestors_of_Tehamana_OR_Tehamana_Has_Many_Parents_(Merahi_metua_no_Tehamana)_-Google_Art_Project.jpg >. Acesso em: 10 ago. 2017. 
Figura 4: Trecho da conversa com um dos predadores identificados através da campanha Sweetie. Fonte: <https://www. terredeshommes.nl/sites/ tdh/files/uploads/research_report.pdfs. Acesso em: 10 ago. 2017. o voyeur é também o objetivo da agência Lemz ao desenvolver a campanha publicitária Sweetie, neste caso, fazer ver o criminoso consumidor de performances sexuais de crianças por webcam. O evento visual é reorganizado e aquele que estava para ver, para consumir imagens, torna-se ele o objeto de visão, de investigação.

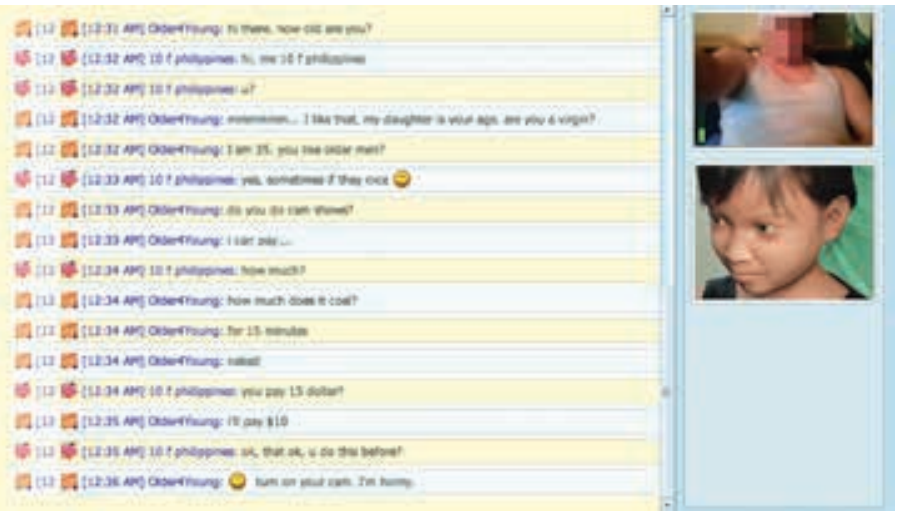

Imerso na realização de seus desejos, embriagado com o espetáculo proibido de corpos infantis, o predador sexual não percebe que ele, também, está sendo vigiado por pesquisadores com a expectativa de identificá-lo, processá-lo e prendê-lo pelos seus atos. Através de pistas dadas pelos predadores na interação com o avatar Sweetie, a equipe da ONG Terre des Hommes busca na própria rede outras informações que possam confirmar sua identidade, um rosto, dados de redes sociais, participações em fóruns, todo e qualquer rastro deixado na internet. Segundo a ONG não foi utilizada nenhuma estratégia de hacking ilegal, mil "predadores" foram identificados utilizando-se para isso apenas uma técnica chamada social hacking, que usa as poucas informações obtidas das pessoas para rastreá-las através de bancos de dados públicos online, como redes sociais, por exemplo (WEBCAM CHILD SEX TOURISM..., 2013).

Ao demonstrar que, embora seja um processo complexo, é possível identificar predadores sexuais na web, Sweetie pode contribuir para intimidar sujeitos que incorrem neste tipo de crime. Quebra-se, assim, a sensação de anonimato, ainda vigente na rede, levando-os a considerar que podem ser vigiados. Como disse Foucault (1987), a vigilância foi uma estratégia de poder fundamental para a sociedade disciplinar, 
e parte de seu funcionamento é difundir a crença de que todos podem estar sendo vigiados a todo instante. Mesmo que essa vigilância não seja materializada pelo olhar de um guarda, os indivíduos introjetam esta vigilância avaliando continuamente sua conformação às normas. Cabe, apenas, averiguar se, ao contrário das expectativas daquele dispositivo panóptico de poder, a atual expectativa desses sistemas de vigilância é menos moral do que policial, como suspeita Sibilia (2012).

Hoje, assim como no século XIX, fundamental para tal estratégia de poder é que, em paralelo à possibilidade de ver todos, também se desenvolva a capacidade de identificar o indivíduo em meio à multidão. Como explica Gunning (2004), as fotografias de rosto e corpo passaram a ser amplamente empregadas a partir desse tipo de interesse no século XIX. "O objetivo de tal identificação é 'fixar a personalidade humana, dar a cada ser humano uma identidade, uma individualidade, certa, durável, invariável, sempre reconhecível e sempre capaz de ser provada"' (GUNNING, 2004, p. 42). Mas foi necessário molecularizar, construir arquivos com informações meticulosamente organizadas e associadas configurando identidades.

Novas tecnologias, como a rede mundial, criaram uma arquitetura distinta das cidades do século XIX, na qual o anonimato parece ainda mais plausível. Contudo, o impulso para vigilância permanece, em muitos sentidos amplificou-se estimulando desenvolvimentos tecnológicos paralelos. De certa forma Gunning (2004) aponta interesses que possibilitaram o desenvolvimento das tecnologias de vigilância de hoje. Ubíquas, diferenciam-se também ao potencializar o poder das câmeras com a capacidade não apenas de filmar, fotografar, mas de identificar indivíduos através de tecnologias biométricas, seja pelo movimento corporal, seja pela identificação da face.

Redes sociais como o Facebook tornaram tecnologias como a identificação biométrica da face cotidianas, associando-as a bancos de dados que guardam informações sobre grande parcela da população mundial. Como vimos acima, redes sociais não são apenas um novo espetáculo, mas uma nova máquina de vigilância. A equipe por trás de Sweetie se aproveitou disso para realizar uma vigilância punitiva.

Sweetie se caracteriza como um tipo de vigilância que identifica sujeitos e encaminha para a punição, mas é também uma tecnologia que revela preocupação com o ambiente social que é a internet hoje. A denúncia de pedofilia para justificar o estabelecimento de estratégias de vigilância é bastante 
persuasiva em virtude da sensibilidade ampla que temos em relação à proteção de jovens e crianças. Ninguém questiona a importância de protegermos jovens e crianças. Contudo, se Sweetie aponta os perigos assim como as benesses da vigilância na web, artistas e teóricos, por outro lado, preocupam-se também em lembrar-nos de que ainda assim precisamos vislumbrar perigos que o excesso de vigilância pode trazer para uma sociedade democrática.

Baseados nesta premissa os artistas Leo Sevaggio e Adam Harvey desenvolveram ações contra as tecnologias de identificação facial. Na obra URME (2014), Sevaggio convida as pessoas a proteger suas identidades escondendo os rostos usando uma máscara baseada no rosto do próprio artista. Em CV Dazzle (2010), Harvey desenvolve padrões de maquiagem e corte de cabelo que tornam os rostos irreconhecíveis aos programas de identificação facial.

Como ressalta Silveira (2009, p. 121), "existem projetos de leis em vários países que visam obrigar os provedores de acesso à internet a proibirem o uso das redes sem identificação positiva dos cidadãos", o que seria feito através do vínculo do IP do computador a uma identidade. Contudo, este mesmo autor faz o alerta de que apesar de combatermos o anonimato sob o pretexto de prevenir crimes, podemos estar cometendo um erro maior ao destruir a privacidade com excesso de vigilância. Desta forma, percebe-se um certo receio acompanhando a escalada do poder de vigilância da rede.

O que pensar sobre esse receio certamente permanecerá uma importante pauta de debate nos anos vindouros, debate sobre o qual a Cultura Visual certamente continuará se interessando. Que arquitetura social emergirá na internet? De que forma essa arquitetura social organizará as experiências visuais? Tornar-nos-emos dados eternamente vigiados em tudo que fazemos e pensamos? Estas são questões fundamentais para a análise da relação entre experiência visual e cultura daqui para frente. A internet não pode tornar-se espaço livre para práticas de crimes como esses que Sweetie denuncia. Por outro lado, como proteger o valor da privacidade?

\section{Sobre crenças nas imagens, o poder do "ao vivo", tele presença e desejo de controle...}

Outro aspecto crucial da campanha desenvolvida pela agência de publicidade Lemz, e que interessa à Cultura Visual, é o modo como ela apropria-se de crenças sobre certas 
imagens. Vivemos em uma sociedade ocularcêntrica na qual práticas de produção de significado que preenchem imaginários e conquistam nossa atenção são veiculadas visualmente (CAMPOS, 2007). Para Mirzoeff (1999, p. 3), estudar a "genealogia, a definição e função" desse contexto que ele define como "o cotidiano pós-moderno" é o objetivo do campo de estudos da Cultura Visual. Nesse sentido restrito, aspecto fundamental para entender nossa cultura é a investigação sobre nossa relação com imagens.

Ao gerar determinados efeitos, ou seja, ludibriar indivíduos que veem a campanha, Sweetie tira proveito de expectativas que construímos sobre a veracidade das imagens. Como lembra Flores (2012, p. 72), a certeza de que a perspectiva linear representaria fielmente o real marcou "não só a pintura como também todas as técnicas e dispositivos visuais que desde a perspectiva à fotografia e ao cinema haviam intensificado a crença em que as imagens semelhantes traduziam a verdade e promoviam melhor contacto com o mundo". Nossas crenças sobre a perspectiva linear continuam impregnando nossa relação com tecnologias como a câmara escura, a câmara fotográfica e a de vídeo. Ao tirar partido dessas convenções e expectativas em relação aos códigos visuais que pautam estas tecnologias e a webcam, a ação promovida pela agência Lemz através do modelo 3D Sweetie tornou-se efetiva.

Assim como Flores (2012, p. 66), defendemos que ao contrário de cópias do real, "cabe-nos compreendê-las [as imagens produzidas na lógica da perspectiva linear] como modelos de aproximação e de tradução; no lugar de confiar na imagem, [devemos] apenas entendê-las como um modelo de compreensão do mundo". Kosminsky (2008, p. 78) argumenta que o estabelecimento da perspectiva foi fundamental para o desenvolvimento da ciência, não pela sua suposta neutralidade/objetividade, mas por servir como uma "regra ou esquema combinatório que garantisse a relação lógica do sistema de símbolos pictóricos". Acrescentando esta convenção à possibilidade de "duplicação exata de uma imagem" através das gravuras, possibilitou-se "uma racionalização do olhar - que pode ser considerado como o mais importante evento do renascimento" (KOSMINSKY, 2008, p. 80). Perspectiva e gravura permitiram, respectivamente, o estabelecimento de imagens com código e a possibilidade de serem difundidas e compartilhadas.

Embora nasça assim, o poder de Sweetie de ludibriar seus espectadores não se estabelece unicamente pela crença 
na sua semelhança com o real. O "ao vivo", segundo Wolff (2005), se configura como se não fosse imagens, mas como janelas transparentes, como se fora o real em si. Mais do que a crença na iconicidade/semelhança da perspectiva, age a favor da crença nas imagens "ao vivo" a expectativa de indicialidade (fé desenvolvida com a máquina fotográfica) e de sincronicidade (difundida pela televisão). Por esta razão, Wolff (2005) ressalta que hoje em nenhum tipo de imagem a ilusão da transparência é maior do que nas imagens "ao vivo". Chegamos ao ponto de sentir ou considerar contra intuitivo colocá-las em dúvida. Por simular uma cena ao vivo, Sweetie amplifica seu poder de ludibriar.

Do ponto de vista da Cultura Visual, cabe lembrar que nas experiências "ao vivo" possibilitadas por webcams interagimos com imagens, com telas. Mesmo evitando cair em algum tipo de iconoclastia, é necessário assumir que em função da facilidade com que podem ser produzidas, transformadas e com que circulam, experiências visuais mediadas por imagens têm amplo poder para nos ludibriar, para manipular. Um pouco de ceticismo é sempre salutar.

É possível defender que as imagens, eletrônica e digital, devem auxiliar na promoção da dúvida em relação às próprias imagens. Machado (2001, p. 49), por exemplo, avalia que em virtude dessas imagens (eletrônica e digital) existirem apenas como resultado do processamento de um programa, logo devemos concluir que "tudo não passa de corrente elétrica modulada". O autor acredita que "tudo isso permitirá superar a crença ingênua e largamente disseminada de que a fotografia é um atestado de veracidade das coisas" (MACHADO, 2001, p. 54). Concordamos com Machado e lembramos que o modelo 3D Sweetie é um exemplo das possibilidades da tecnologia digital.

Mas, como o próprio Machado (2001) observa, há pouco avanço se estagnarmos na concepção de que imagens digitais são menos reais que imagens analógicas. É importante destacar, como o faz Machado (2001, p. 54), que toda e qualquer imagem é "um sistema de signos, uma 'linguagem' com a qual se pode 'escrever' verdades e mentiras, como em qualquer outro código significante". Códigos em ação também estão presentes nas tecnologias analógicas e, nesse sentido, elas também têm um programa que as gera e condiciona a produção de um tipo de imagem (FLUSSER, 1985). Cabe, portanto, estarmos atentos a esses códigos para usá-los, subvertê-los e, sobretudo, colocá-los em dúvida. 
Todavia, Sweetie não simula uma imagem "ao vivo" qualquer, as relações que se estabelecem por meio de webcams são bastante distintas daquelas que se estabelecem ao vermos um "ao vivo" de telejornal, por exemplo. Sweetie faz referência a um dispositivo visual cujo apelo não se explica unicamente pela expectativa de veracidade de suas imagens. Manovich (2001) ressalta que o poder de algumas representações está menos na capacidade de ilusão do que na possibilidade de servirem como instrumentos para a ação. O autor faz a seguinte descrição do que chama de imagens de telepresença:

Telepresença provém da habilidade de manipular remotamente a realidade física em tempo real através de suas imagens. O corpo do teleoperador é transmitido, ao vivo, para outra localização onde pode agir em nome desse sujeito - reparando uma estação espacial, fazendo escavação submarina ou bombardeando uma base militar no Iraque ou Iugoslávia. Então, a essência da telepresença é que essa é anti-presença. Eu não tenho de estar fisicamente presente em uma localidade para afetar a realidade nesta localidade. Um melhor termo seria teleação. Agir a distância. Ao vivo. (MANOVICH, 2001, p. 166-167).

Webcams promovem telepresença na medida em que permitem, através da troca ao vivo, informações visuais de lugares remotos possibilitando que sujeitos emitam à distância ordens ou comentários que levem à manipulação física de corpos e ambientes, produzindo efeitos psicológicos em outros sujeitos. Segundo Lopes (2013), em sites de pornografia via webcam é prática comum para indivíduos que se exibem, especialmente quando tal exibição envolve pagamento em dinheiro, que sejam constantemente interpelados pelos espectadores requisitando gestos, atos etc. O autor descreve esta prática como "pornografia-fluxo, pornografia-processo, pornografia-acontecimento” (LOPES, 2013, p. 4), pois não há roteiro prévio e os receptores/espectadores interveem intensamente na produção das imagens. Ainda de acordo com Lopes (2013, p. 10), em virtude dessa expectativa:

uma das sentenças de teor mais acusatório que podem ser proferidas durante um show no Cam4 [o maior site de exibição de sexo por webcam] é "it is a video", ou seja, a suspeita de que, ao contrário da convenção estabelecida, trata-se ali de uma gravação, obra fechada, não live webcam. 
rente, rompendo-se inteiramente a relação da imagem com o real" (ARANTES, 2005, p. 76-77).

Embora a campanha Sweetie denuncie o abuso de crianças reais, a tecnologia de imagem de síntese $3 \mathrm{D}$ que permite a criação do avatar Sweetie é a mesma utilizada em sites com conteúdo pornográfico, de vídeos, jogos e redes sociais (como o Second Life) nos quais é possível, além de ver, interagir com modelos 3D em ambientes de realidade virtual, incluindo, obviamente, simulações de sexo. Esses sites deixam evidente que mesmo existindo unicamente como imagens, sem qualquer promessa de indício de uma realidade, essas representações têm valor no mercado do sexo.

De certa forma, parece-nos que a ideia de realismo das imagens pornográficas pode nos fazer ignorar aspectos de sua recepção. Involuntariamente Sweetie nos faz pensar sobre nossa relação com imagens por si próprias, sobre os prazeres de uma relação erótica com imagens. Imagens que, mesmo que sigam códigos realistas, são na maioria das vezes da ordem do hiper-real, ou seja, menos importa indiciar algo objetivo, pertencente ao mundo, do que excitar a subjetividade do observador.

A imagem pornográfica dá potencialidades à indústria do sexo as quais devem ser investigadas. Segundo Gunning (2004, p. 35), vale "repensar a história da fotografia sem focar unicamente o modo da nova representação tecnológica que ela introduziu, mas considerando seu papel na remodelação de um território no qual sinais e imagens, efetivamente apartados de um referente, circulam e proliferam”. Como imagem, o corpo torna-se "transportável e totalmente adaptável aos sistemas de circulação e mobilidade que a modernidade exigia” (GUNNING, 2004, p. 37). Como imagens, corpos podem ter circulação muito mais ampla.

Além disso, como imagens, os corpos são intrinsecamente mais maleáveis, mais susceptíveis à apropriação e controle do que seres humanos. Dias (2012, p. 2120) ressalta que a pornografia precisa ser crível, contudo, o realismo da pornografia aponta para o hiper-realismo, ou seja, um discurso de excessos. "A pretensão de realidade é transgredir o sexo, a sexualidade do cotidiano, por exemplo, pelo aumento da duração das cenas, pela fantasia, pelo aumento exagerado das genitálias, pela perfeição afetada dos corpos, entre outros”. É importante ressaltar que com o corpo-imagem esse desejo pelo excesso pode quebrar barreiras impostas pelo corpo físico. Em sites como o Second Life, a pornografia 3D explora o impossível para corpos reais. 
As esculturas Hiropon (1997) e My lonesome cowboy (1998), de Takashi Murakami, auxiliam na discussão sobre esta potência testada ao máximo na cultura otako3. Os riscos implícitos ao corpo que passa por uma cirurgia plástica para aumentar os seios não existem para o corpo/imagem dos hentais, quadrinhos pornográficos japoneses, aos quais a escultura Hiropon com seus seios gigantescos faz referência. É evidente que o corpo humano tem limites, barreiras que as imagens não têm, como fica evidente na escultura My Lonesome Cowboy. Esta escultura reflete também o valor conferido pela audiência de sites de pornografia por webcam à abundância de sêmen no gozo de performers masculinos. Como afirma Lopes (2013, p. 12), nesses sites "a abundância do gozo é uma metáfora de virilidade", por isso muitos anunciam suas performances declarando já estarem a dias sem gozar (com status como "3 days load").

Por um lado, Gatto (2007, p. 97) relaciona a pornografia ao medical shot, "uma visão genital e clínica do sexo, similar a uma visita ao ginecologista ou ao urologista", o que ele denomina de meat shot, "uma visão fragmentária e fálica sobre uns corpos sem rosto, objetificados e reduzidos à carnalidade da penetração". Por outro, Lynn Hunt (1993, p. 39) defende que esse aparente realismo revela uma realidade mais que real ao descrever a tendência da pornografia de eliminar a realidade externa em favor de uma "fantasia utópica" na qual "espaço e tempo somente medem a repetição de encontros sexuais e corpos são reduzidos a partes sexuais e à infinita possibilidade de suas variações e combinações". A ideia de Hunt (1993) pode ser identificada e materializada na obra Patchwork hotel 1 (2012) de Till Rabus, uma sobreposição caótica de corpos eróticos.

A experiência erótica proporcionada pela pornografia das imagens de síntese, em especial, ganha não somente uma difusão instantânea global, impossível para um corpo, mas ganha, também, a capacidade de manipulação e controle da experiência visual, possibilitando corpos e interações hiper-reais.

Parece plausível considerar que as relações eróticas que podem ser estabelecidas com imagens independem de elas nos reportarem a algo real, mesmo quando tal relação se pauta em códigos de representação "realística". Para Crary (2012), a modernidade trouxe uma concepção de visão que renega as expectativas empiristas de que a visão seria uma experiência objetiva do real. Trata-se de uma visão subjetiva na qual a subjetividade psíquica/fisiológica do observador determina 
a experiência e não um referente externo, ou seja, trata-se de uma "percepção autônoma apartada de qualquer referente externo" (CRARY, 2012, p. 23). Segundo este historiador da arte e da cultura visual, esta concepção é precondição tanto para o modernismo na arte quanto para a nossa relação com uma série de formas de entretenimento de massa, dentre as quais podemos incluir a pornografia. Crary (2012, p. 23) detalha esta concepção da seguinte maneira:

Com isso, certas formas de experiência visual, em geral consideradas acriticamente como "realistas", vinculam-se a teorias não verídicas da visão, que têm por efeito aniquilar a existência de um mundo real. Apesar das tentativas de autenticá-las e naturalizá-las, a experiência visual perdeu no século XIX as pretensões apodícticas de que se valia a câmara escura para estabelecer a verdade. Em um nível superficial, as ficções do realismo atuam imperturbadas, mas os processos de modernização no século XIX não dependiam dessas ilusões. Novos modos de circulação, comunicação, produção, consumo e racionalização exigiram e deram forma a um novo tipo de consumidor-observador.

Nesse sentido, o consumidor-observador moderno valorizaria e avaliaria as experiências visuais menos pelo que elas dizem sobre um mundo externo e mais pela medida em que o estimulam subjetivamente, explorando sua fisiologia, provocando efeitos corpóreos, reagindo com suas fantasias, sonhos, desejos. Tal posição ecoa a de Yves de La Taille (2009, p. 29), segundo a qual o mundo real "adquire em grau cada vez maior os traços reservados ao mundo ficcional da arte” e, nesse sentido, "o homem pós-moderno trocou a avaliação ética do mundo pela avaliação estética”.

Essa disposição à avaliação estética à qual se refere La Taille (2009) não traria implicações para a relação que a nossa sociedade assume com essa que é uma de suas maiores indústrias, a indústria pornográfica? $\mathrm{O}$ foco na imagem como sendo unicamente um meio de estimulação subjetiva é evidente nas imagens de síntese $3 \mathrm{D}$, um dos novos produtos dessa indústria. Porém, em que medida não será este o foco na busca por imagens pornográficas?! Em que medida consumidores de pornografia veem nessas imagens pessoas com direitos, pessoas com as quais devem ser éticos? Ou, será que veem apenas imagens, apenas objetos que usam para estimular e gerar prazer? Cabe refletirmos sobre os efeitos subjetivos 
de uma sexualidade cada vez mais marcada pela relação com imagens. Cabe refletirmos, ainda, sobre as possíveis consequências políticas e sociais de interações com seres humanos, em especial em casos como o das crianças das Filipinas, as quais não devem ser vistas apenas como imagens, como objetos que podem ser manipulados para autogratificação de outros.

\section{Apontamentos finais}

Em um mundo globalizado, marcado por fluxos de informação digitais que difundem imagens, as pessoas vivem, vendem e compram, experimentam novas formas de sexualidade, cometem crimes, reproduzem desigualdades. Analisar fenômenos visuais contemporâneos como aqueles referenciados por Sweetie é tarefa complexa, porém instigante. Esta tarefa fundamental para o campo da Cultura Visual precisa ser enfrentada caso queiramos posicionarmo-nos criticamente diante do modo como se organizam eventos visuais e suas imagens, caso queiramos investigar e buscar compreender seus efeitos subjetivos, seus potenciais e riscos para a sociedade contemporânea.

É claro que a educação da cultura visual pode ser um estimulador de debates sobre a arquitetura das experiências visuais possibilitada pela web, sobre as desigualdades de classe, de gênero e étnicas que determinam muitas vezes as imagens distribuídas globalmente, assim como sobre os efeitos subjetivos para aqueles indivíduos transformados em objetos para o prazer de outros, e sobre os efeitos disso para uma juventude cada vez mais exposta à pornografia. Parece evidente que a escola tem um papel a desempenhar na educação sexual e, portanto, deveria motivar, especialmente os jovens, a refletirem criticamente sobre a indústria da pornografia. Abreu cita "visualidades cotidianas as quais, muitas vezes, a escola finge não conhecer ou simplesmente ignora" (2015, p. 3937). Entre essas visualidades certamente estão imagens associadas à sexualidade. Todavia permanecem muitas dúvidas sobre como enfrentar tais questões, especialmente no contexto escolar, ainda marcado por um conservadorismo que privilegia o silenciamento de tais debates.

\section{NOTAS}

1 O termo "predadores" é descrito pela ONG como mais adequado do que "pedófilos", primeiro por que pedofilia descreve a atração sexual por aqueles com idade pré-púbere, nesse sentido alguém pode ter este distúrbio, porém 
não cometer crimes. Mais do que isso, segundo a ONG há motivos para acreditar que entre os que cometem crimes de natureza sexual contra crianças existem também aqueles que não se encaixam na descrição específica do distúrbio da pedofilia (WEBCAM CHILD SEX TOURISM..., 2013).

2 Este é um ponto importante para a história da pornografia. Segundo Kendrick (1987), a ascensão dos museus abertos a todos foi igualmente o momento da criação dos "museus secretos", espaços nos quais pinturas, esculturas, livros e quaisquer outros objetos considerados perigosos para a moral da época, em função do conteúdo erótico, eram guardados de forma a resguardar a sua visão apenas para homens da elite intelectual, protegendo, assim acreditavam, as classes trabalhadoras, mulheres e crianças.

3 Otako se refere às pessoas que, de tão fanáticas por animes (desenhos animados japoneses), vídeo games, mangás (histórias em quadrinho japonesas) ou outros produtos da indústria cultural japonesa, tendem a se isolar nos universos fantásticos dessas narrativas.

\section{REFERÊNCIAS}

ABREU, C. Imagens que não afetam: questões de gênero no ensino da arte desde a perspectiva crítica feminista e da cultura visual. In: ENCONTRO DA ANPAP, 24., 2015, Santa Maria. Anais... Santa Maria: Anpap, 2015. p. 3927-3942.

ARANTES, P. @rte e mídia: perspectivas da estética digital. São Paulo: Editora Senac, 2005.

BENNETT, T. The Exhibitionary Complex. New Formations, Chadwell Heath, n. 4, p. 73-102, spring 1988.

BERGER, J. Modos de ver. Rio de Janeiro: Rocco, 1999.

BRUNO, F. Máquinas de ver, modos de ser: visibilidade e subjetividade nas novas tecnologias de informação e de comunicação. Revista da FAMECOS, Porto Alegre, v. 24, p. 110-124, 2004.

CAMPOS, R. M. D. O. Pintando a cidade: uma abordagem antropológica ao graffiti urbano. 2007. $512 \mathrm{f}$. Tese (Doutorado em antropologia) - Universidade Aberta, Lisboa, 2007.

CHARRÉU, L. Imagens globais, cultura visual e educação artística: impacto, poder e mudança. In: MARTINS, R.; TOURINHO, I. (Org.). Cultura das imagens: desafios para a arte e para a educação. Santa Maria: Editora da UFSM, 2012. p. 39-54.

CRARY, J. Spectacle, attention, counter-memory. October, Cambridge, v. 50, p. 97-107, Outono 1989.

Técnicas do observador: visão e modernidade no século XIX. Rio de Janeiro: Contratempo, 2012.

DEBORD, G. A sociedade do espetáculo: comentários sobre a sociedade do espetáculo. Rio de Janeiro: Contraponto, 1997.

DIAS, B. Pré-acoitamentos: os locais da arte/educação e da cultura visual. In: MARTINS, R. (Org.). Visualidade e educação. Goiânia: FUNAPE, 2008. p. 37-53. 
DIAS, B. Ensinando fora do eixo: cultura visual queer. In: ENCONTRO DA ANPAP, 21., 2012, Rio de Janeiro. Anais... Rio de Janeiro: Anpap, 2012. 2111-2125.

DUBOIS, R. Luke. A more perfect union. 2011. Conjunto de 39 gravuras, 38 mapas, 1 título. Pigmento-tinta no photo rag. 61 de altura x 91,5 cm, cada. Edição de 6 .

FLORES, V. A imagem técnica e a sua crença: a confiança visual na era digital. Lisboa: Editores Nova Vega, 2012.

FLUSSER, V. Filosofia da caixa preta: ensaios para uma futura filosofia da fotografia. São Paulo: Hucitec, 1985.

FOUCAULT, M. Vigiar e punir: o nascimento da prisão. 32. ed. Petrópolis: Vozes, 1987.

GATTO, F. G. Pospornografia. Estudios Visuales, Murcia, n. 5, p. 95-106, jan. 2008.

GUNNING, T. O retrato do corpo humano: a fotografia, os detetives e os primordios do cinema. In: CHARNEY, L.; SCHWARTZ, V. R. (Org.). O cinema e a invenção da vida moderna. 2. ed. São Paulo: Cosac Naif, 2004. p. 33-66.

HAKIM, Catherine. Erotic capital. European Sociological Review, Oxford, v. 26, p. 499-518, 2010.

HARVEY, Adam. CV Dazzle. 2010. 5 padrões de camuflagem compostos por maquiagens e cortes de cabelo que impedem detecção facial computacional.

HERNANDEZ, F. Catadores da cultura visual: proposta para uma nova narrativa educacional. Porto Alegre: Editora Mediação, 2007.

HUNT, L. The invention of pornography: obscenity and the origins of modernity, 1500-180o. New York: Zone Books, 1993.

ILLERIS, H.; ARVEDSEN, K. Fenômenos e eventos visuais: algumas reflexões sobre currículo e pedagogia da cultura visual. In: MARTINS, R.; TOURINHO, I. (Org.). Cultura das imagens: desafios para a arte e para a educação. Santa Maria: Editora da UFSM, 2012. p. 283-310.

JAGODZINSKY, J. As negociações da diferença. In: GUINSBURG, J.; BARBOSA, A. M. (orgs.). O pós-modernismo. São Paulo: Perspectiva, 2005. p. 661-689.

KEEN, A. Vertigem digital: por que as redes sociais estão nos dividindo, diminuindo e desorientando. São Paulo: Zahar, 2012.

KENDRICK, W. M. The secret museum: pornography in modern culture. New York: Viking, 1987.

KINCHELOE, J.; MCLAREN. Repensando a teoria crítica e a pesquisa qualitativa. In: DENZIN, N.; LINCOLN, Y. (Org.). O planejamento da psequisa qualitativa: teorias e abordagens. Porto Alegre: Artmed, 2006. p. 281-313. 
KOSMINSKY, D. C. O olhar inocente é cego: a construção da cultura visual moderna. Tese (Doutorado em Artes e Design) - Pontifícia Universidade Católica do Rio de Janeiro: Rio de Janeiro, 2008.

LA TAILLE, Y. D. Formação ética: do tédio ao respeito de si. Porto Alegre: Artmed, 2009.

LOPES, M. Pornografia amadora em tempo real: observações preliminares sobre o $\mathrm{CAM}_{4}$. Simpósio em tecnologias digitais e sociabilidade. Salvador: [s.n.]. 2013. p. 1-14.

MACHADO, A. Máquina e imaginário: o desafio das poéticas tecnológicas. 3. ed. São Paulo: Editora da Universidade de São Paulo, 2001.

MANOVICH, L. The Language of New Media. London: MIT Press, 2001.

MIRZOEFF, N. An introduction to visual culture. London: Routledge, 1999.

MITCHELL, W. J. T. Showing seeing: a critique of visual culture. Journal of visual culture, Thousand Oaks, v. 1, n. 2, p. 165-181, 2002.

MULVEY, L. Prazer visual e cinema narrativo. In: MACEDO, A. G.; RAYNER, F. (Org.). Género, cultura visual e performance. Minho: Edições Húmus, 2011. p. 121-132.

POLLOCK, G. A modernidade e os espaços da feminilidade. In: MACEDO, A. G.; RAYNER, F. (Org.). Género, cultura visual e performance. Minho: Edições Húmus, 2011. p. 53-68.

RUBIN, Ben; HANSEN, Mark. Listening post. 2003. Instalação eletrônica audiovisual composta por 231 telas. Encontra-se exposta no Whitney Museum of American Art, Nova York, EUA.

SIBILIA, P. O show do eu: a intimidade como espetáculo. Rio de Janeiro: Nova Fronteira, 2008.

Redes ou paredes: a escola em tempos de dispersão. Rio de Janeiro: Contraponto, 2012.

SILVEIRA, S. A. D. Redes cibernéticas e tecnologias do anonimato. Comunicação E Sociedade, v. 30, n. 51, p. 113-134, jan./ jun. 2009.

SEVAGGIO, Leo. URME. 2014. Instalação interativa composta por máscaras protéticas $3 \mathrm{D}$, webcams, telas de computador, máscaras de papel e um aplicativo de reconhecimento facial. STEHLI, Jemina. Strip. 200o. Série de 56 fotografias coloridas, formato $32 \times 27 \mathrm{~cm}$.

ULMAN, Amalia. Excellences \& Perfections. 2014. Performances fotográficas com 175 fotografias e legendas postadas na rede social Instagram. A obra foi lançada como parte do projeto New York's first look program, de 2014. 
WEBCAM CHILD SEX TOURISM - Becoming Sweetie: a novel approach to stopping the global rise of Webcam Child Sex Tourism. Terre des Hommes, 2013. Disponivel em: <https:// www.terredeshommes.nl/sites/tdh/files/uploads/research_ report.pdf>. Acesso em: 19 dez. 2017.

WOLFF, F. Por trás do espetáculo: o poder das imagens. In: NOVAES, A. Muito além do espetáculo. São Paulo: Editora Senac, 2005. p. 16-45.

YOSHIYUKI, Kohei. The park. 1971-1973. Série de 62 fotografias em preto e branco de 31,12 cm de altura por $46,51 \mathrm{~cm}$ de comprimento. Coleção SFMOMA. Fotografias publicadas em várias edições, sendo a mais recente a do livro The Park 1971-73 pela editora Osiris de Tóquio, em 2011, que conta com 14 fotografias $30 \mathrm{~cm}$ de altura $\mathrm{x} 42 \mathrm{~cm}$ de comprimento.

\section{PABLO PETIT PASSOS SÉRVIO}

pservio@gmail.com

Doutor em Arte e Cultura Visual pela Universidade Federal de Goiás. É professor efetivo do Departamento de Artes Visuais da Universidade Federal do Maranhão. Tem publicado capítulos de livros e artigos em revistas nacionais e internacionais.

\section{RAIMUNDO MARTINS}

martins.raimar@gmail.com

Doutor em educação/artes pela Southern Illinois University (EUA). É professor titular da Faculdade de Artes Visuais da Universidade Federal de Goiás e pesquisador permanente do Programa de Pós-graduação em Arte e Cultura Visual. É autor (com Irene Tourinho) da coleção Cultura Visual e Educação publicada pela Editora UFSM. Tem publicado capítulos de livros e artigos em revistas nacionais e internacionais. 